\title{
Neurologic manifestations and COVID-19
}

\section{Manifestaciones neurológicas y COVID-19}

Viroj Wiwanitkit*

D. Y. Patil University, Community Medicine Department, Pune, India

In the article by Jiménez-Ruiz et al., entitled "Neurologic manifestations of COVID-19", it was concluded that "we must bear in mind infectious and non-infectious complications that affect the nervous system such as encephalitis, seizures, Guillain-Barre syndrome, disseminated encephalomyelitis and hemorrhagic leukoencephalitis, which are disorders that can occur during or after viral infections. A neurological symptom could be the first manifestation of COVID-19." In fact, COVID-19 can give rise to numerous atypical presentations, making diagnosis difficult; ${ }^{2}$ however, concurrent neurological problem represents a significant complication. A patient with COVID-19 might have an underlying neurological disorder, such as epilepsy or cerebrovascular infarction, which could lead to a more complex clinical course. In addition, there is the possibility of another concurrent medical disorder, such as coinfection, which can trigger neurological disorders in patients with COVID-19. A good example is concurrent dengue and COVID-19 infection. ${ }^{3}$

\section{References}

1. Jiménez-Ruiz A, García-Grimshaw M, Ruiz-Sandoval JL. Manifestaciones neurológicas de COVID-19. Gac Med Mex. 2020;156:257.

2. Tin SS, Wiwanitkit V. Uncommon atypical presentations of COVID-19: Important and should not be under recognized! J Health Med Sci Res. 2020:38:153-158.

3. Magalhaes T, Chalegre KDM, Braga C, Foy BD. The endless challenges of arboviral diseases in Brazil. Trop Med Infect Dis. 2020;5:E75.
Gac Med Mex. 2020;156:360 Contents available at PubMed www.gacetamedicademexico.com 